\title{
Hedging Oil Prices with Renewable Energy Indices: A Comparison between Various Multivariate Garch Versions
}

\author{
Asma Abdallah and Ahmed Ghorbela* \\ Department of Quantitative Methods, CODESI Laboratory, Tunisia
}

Submission: January 23, 2018; Published: April 25, 2018

*Corresponding author: Ahmed Ghorbel, Department of Quantitative Methods, CODESI Laboratory, Faculty of Economics and Management of Sfax, Sfax, Tunisia, Email: ahmed_isg@yahoo.fr

\begin{abstract}
Increasing greenhouse gas emissions, rising and exhaustibility oil prices has accumulated the importance of looking for alternative energy sources. In this work, our objective is to study in a first step the link and interactions between oil market and the renewable energy stock market in terms of volatility, then in a second step to determine the best hedging strategy in the oil market by the renewable energy indices. Our methodology consists to estimate the volatility of the variation of oil prices on the renewable energy indices as well as the coefficient of correlation based on a multivariate GARCH model. Several versions of this model are used to calculate the variances as well as the conditional correlations to calculate the hedging ratio and then determinate the best hedging strategy. The empirical results show that the volatility of alternative energy market can be influenced by the change in oil prices and vice versa. In addition, the hedging ratio as well as the weighting coefficient varies from pair Oil/Renewable Energy to another, from one period to another and from one MGARCH version to another. Hedge against the risk of fluctuation of oil is effective with the use of renewable energy markets. The BEKK-GARCH model is more efficient compared to other versions in reducing Oil-Renewable Energy portfolio risk.
\end{abstract}

Keywords : Volatility transmission; Renewable energy indices; Hedging strategy; Optimal portfolio weight; Multivariate GARCH;BEKK representation

Abbreviations: GCE: Global Clean Energy Index; ERIX: European Renewable Energy Index; NEX: New Energy Global Innovation Index; HE: Hedge Effectiveness Coefficient; BEKK: Baba-Engle-Kraft-Kroner; CC: Constant Conditional Correlation; QMLE: Quasi-Maximum Likelihood Estimation

\section{Introduction}

Currently, Energy has become part of our daily lives in one way or another. At a national level, the importance of energy is further amplified as energy is now a necessity for smooth functioning of our daily work and personal chores [1]. Then, without energy most developing and industrial societies would be unable to maintain their economic growth and subsistence. Few previous studies have suggested that rising oil prices negatively affect stock market returns and economic activities. Thus, it slows down cash flow and reduces stock prices. However, there are several industries that benefit from this increase; it mainly refers to clean, alternative, or renewable energy industry [2]. In fact, over the last decades, the global massive use of fossil fuels has grown more than twenty times, which has caused two major problems [3]:

I. The potential depletion of fossil energy sources.

II. And increasing in greenhouse gas emissions which have an undeniable impact on pollution and global warming.
So, the world today is motivated to seek out clean energy sources. The international Energy Agency (IEA) predicts that the demand for renewable energy will grow at a compound average annual growth rate of $7.3 \%$ between 2007 and 2030 [4]. Moreover, the use of energy in all its forms (electricity generation, industry use, transportation and residential use) is one of the main raisons for economic growth and prosperity. So conforming to the EIA (Energy Information Administration), published in the international Energy outlook, 2013, it was expected that global energy consumption will increase by $56 \%$, between 2010 and 2040 [1]. Reflecting their leading status in the increasing satisfaction of the world's energy needs. As countries grow and prosper, their demand for energy increases as well.

Modeling and predicting volatility is at the heart of modern finance as correlation and volatility estimations are necessary for derivate pricing, portfolio optimization, hedge and risk management. So far, there are few things about the dynamics 
of clean energy price volatility and the possible linkages between these and other major financial markets, such as the oil market [5]. So in order to know whether an investment in renewable energy stocks is more or less attractive, investors should establish how the dynamics of oil prices influence the performance of renewable companies. In particular, investors need to assess the potential risks of decline or increase due to the oil prices. Therefore, understanding how fossil fuel prices coagulate with clean energy prices is an important issue which worries investors and policymakers to the same extent [6].

In recent years, the relationship between oil prices and stock market returns has received enormous attention and has made the sector of renewable energy one of the most promising industries [7]. In fact, there are very few studies supporting on the relationship between oil prices and alternative energy prices. Previous works have treated this relationship using different econometric methods. In view of the above, this study aims to approach the issue of the transmission of oil shocks on the clean energy market in first step, then to determine the best hedging strategy on the oil market by each index of renewable energy. The optimal strategy need the determination of the optimal hedge ratio or the weighting coefficient, which in turn determines the correlation coefficient and the volatility function in both markets in question. To achieve this goal, we will adopt the approach of estimating volatilities and correlation coefficient based on a multivariate GARCH model. Several versions of this model are used to calculate the variance as well as the conditional correlations and then the hedge ratio.

As a result, we bring out a series of questions that constitute the problematic of our study:

To what degree a shock from oil market can affect the renewable energy indices and a shock from renewable energies can affect the oil market?

a. Is the relationship between oil market and the renewable energy market unidirectional or bidirectional?

b. What optimal hedging strategy can be adopted?

In order to provide answers to the questions above, our study is organized as follows: section 2 gives an overview of past studies. In Section 3, we present multivariate GARCH models. Section 4 provides data descriptions. The performance analysis is described in section 5. Then, section 6 and 7 discusses empirical findings. Finally, conclusions, implications and future research opportunities are provided in the last section.

\section{Literature review}

Even with the importance of oil prices in determining the alternative energy stock prices and the investment profitability of renewable energy companies, the existing literature on the relationship between oil and renewable energy values and their implications stocks is still relatively scant. In this section, attention will be paid to the theoretical and empirical literature on the relationship between oil markets and clean energy markets in terms of yield and volatility by some authors on the subject. In the bellow, we summarize the main characteristics of the existing literature.

Henriques \& Sadorsky [8] used an autoregressive vector model to account for the relationship between oil prices, alternative energy prices, technology stock prices and interest rates for the period from January 2001 to May 2007, finding evidence of Granger's causality from crude oil price to stock prices of renewable energy companies. They also found that the behavior of renewable energy stock prices closely mirrored those of technology stock prices. In line with Henriques \& Sadorsky [8], Managi \& Okimoto [2] analyze the relationship between oil prices, clean energy stock prices and technology stock prices using Markov-Switching VAR model. They found, before late 2007, oil prices had no effect on clean energy stock prices. But thereafter, higher oil prices had a positive impact. Using a four multivariate GARCH models (BEKK, Diagonal, CCC and DCC), Sadorsky [5] studied dynamics between oil prices and clean energy stock prices. He finds that stock prices of alternative energy companies correlate more closely with technology stock prices than with oil prices. Finding also that oil was a useful hedge for clean energy stocks. Kumar et al. [9] confirm these findings by using Toda \& Yamamoto [10] version of extend VAR framework. They noted that raising oil prices, interest rates and technology stock prices, unlike carbon prices, positively influence alternative energy stock prices. Likewise, for Chinese energy-related stocks, Broadstock et al. [11] reported that oil price dynamics impacted on energy stocks in China, mainly after the beginning of the recent global financial crises, when dependence increased considerably.

Moreover, Sadorsky [12] studies the determinants of renewable company risk between 2001 and 2007; by using a variable beta model. He showed that a rise in oil prices has a positive impact on the beta of renewable energy stocks. There is two recent studies have investigate the impact of the nuclear accident in Japan on both nuclear and alternative energy stocks. Betzer et al. [13] studied the only and unexpected feedback of the German Federal Government to the Fukushima nuclear disaster. The results of the study show that German renewable energy stocks gained nearly $18 \%$ on a beta-adjusted basis over the first trading days after the unpleasant incident, while the German nuclear and conventional energy sector lost about 3.5\% over the same period. In the same way, Frestl et al. [14] examined the impact of the nuclear accident on the alternative energy stocks in France, Germany and Japan, finding positive abnormal returns for clean energy stock returns and significantly negative abnormal performance for nuclear energy companies. In contrast, U.S. nuclear and renewable energy companies do not seem to be noticeably affected by the event.

Analyzing the time-varying beta behavior of cleantechnology stock market indices, Ortas \& Moneva [15] noted 
that these indices achieved higher returns and risks than conventional stock indices. Other studies have analyzed the factors that determine the supply of renewable energy values. Bohl et al. [7] studied the behavior of German renewable energy stocks, noting that they had a significant systematic risk and speculative attacks that bubbles generated before the global financial crisis and European sovereign debt. Furthermore, Wen et al. [16] employed Baba-Engle-Kraft-Kroner (BEKK) model in order to analyze the return and volatility spillover effects between Chinese renewable energy stocks prices and fossil fuel stocks. They reported evidence of significant mean and volatility spillovers between renewable energy stocks, while renewable energy stocks were riskier than fossil fuel stocks.

More recently, Reboredo [6] has pointed signs of different time average and symmetric tail dependence between oil prices and a set of global and sectoral renewable energy indices. Gradually, as the renewable energy sector develops and the current listed companies which go public grow, it is important to have an understanding of the dynamics of these businesses through the volatility. In this paper, four multivariate GARCH models (BEKK, diagonal, constant conditional correlation, and dynamic conditional correlation), are used to model dynamic correlations and the volatility spillovers between oil prices and the stock prices of clean energy companies, are compared and contrasted. It is noted that the VARMA-GARCH constant conditional correlation model fits the data best and this model is then used to construct hedge ratios and optimum portfolio weights.

\section{The empirical model}

The multivariate GARCH model is a mechanism that uses past variances in the explications of future variance. More specifically, it is a method to model the social dependence of volatility. Different versions of MGARCH have been proposed. They differ in the characterization of the conditional variance matrix of a stochastic vector process. In this paper, four multivariate GARCH models (BEKK, diagonal, constant conditional correlation, and dynamic conditional correlation) are used to model the volatility dynamics between the stock prices of clean energy companies, oil prices, technology stock prices and natural gas. The BEKK, which is used as a benchmark, have been proposed by Engle \& Kroner [17] that can be viewed as a restricted version of the VECH model. The other models (diagonal, constant conditional correlation: introduced by Bollerslev [18], and dynamic conditional correlation: suggested by Engle [19]) are approximately easier and can be estimated in two steps. In the first step, univariate GARCH models are used to estimate the variances. In the second step, correlations are modeled based on the standardized residuals from step one.

GARCH is the most popular volatility model proposed by Bollerslev [20]. It allows the conditional variance to be indicated as a linear function of lagged squared error terms and lagged conditional variance terms. A multivariate GARCH model is used to model the time varying variances and covariances. For the diagonal, constant conditional correlation models the conditional variance is supposed to be VARMA-GARCH $(1,1)$ according to Ling \& McAleer [21]. The conditional variance for each return, $i=1, \ldots, m$, following a univariate GARCH process, is written as follow:

$$
h_{i t}=C_{i i}+\sum_{j-1}^{3} \alpha_{i j} \varepsilon_{j-1}^{2}+\sum_{j-1}^{3} \beta_{i j} h_{j, t-1}
$$

Where, $C_{i i}$ is a constant, and $\alpha_{i j}$ and $\beta_{i j}$ are ARCH and GARCH coefficients respectively. Modeling the conditional variances based on Ling \& McAleer [22] approach let big shocks to one variable in order to have influence on the variances of the other variables. This is a suitable specification which allows for volatility spillovers. DCC is not linear, but may be estimated simply using a two step method based on the likelihood function. In the first step, we estimate separately the conditional variance by a univariate GARCH model for each time series. In the second step, the correlations are estimated.

The $\mathrm{k} x \mathrm{k}$ conditional covariance matrix can be written as:

$$
H_{t}=D_{t} R_{t} D_{t}
$$

Where, $R_{t}$ is the time-varying correlation matrix and $D_{t}$ is the diagonal matrix of conditional standard deviations for return series. The matrix $D_{t}$ is obtained from estimating a univariate GARCH model (Eq.1). $D_{t}=\operatorname{diag}\left(h_{1}^{1 / 2}, \ldots, h_{m}^{1 / 2}\right)=\operatorname{diag}\left(\sqrt{h_{i, t}}\right) ; m$ is the number of returns and

$$
t=1, \ldots, n
$$

Accordingly, we can specify the conditional correlation matrix as:

$$
R_{t}=\left\{\left(\operatorname{diag}\left(Q_{t}\right)^{-1 / 2}\right)\right\} Q_{t}\left\{\left(\operatorname{diag}\left(Q_{t}\right)^{-1 / 2}\right)\right\}
$$

Where the $\mathrm{K} \times \mathrm{K}$ symmetric positive definite matrix $Q_{t}$ is given by:

$$
Q_{t}=\left(1-\theta_{1}-\theta_{2}\right)+\theta_{1} \mu_{t-1} \mu_{t-1}^{\prime}+\theta_{2} Q_{t-1}
$$

In which $\theta_{1}$ and $\theta_{2}$ are scalar parameters to capture the effects of previous shocks and previous dynamic conditional correlations on the current dynamic conditional correlation, and $\theta_{1}$ and $\theta_{2}$ are non negative scalar parameters satisfying $\theta_{1}+\theta_{2}<1$, which implies that $Q_{t}>0$. And $\bar{Q}$ is the $\mathrm{K} \times \mathrm{K}$ unconditional correlation matrix of the standardized residuals $\mu_{i, t}$

In the DCC model, the conditional correlation estimator $\rho_{i j, t}$ is given by:

$$
\rho_{i j, t}=\frac{q_{i j, t}}{\sqrt{q_{i i, t} q_{j j, t}}} \sqrt{i, j: 1, \ldots, n ; i \neq j}
$$

Where, $q_{i j, t}$ is the element of the $i^{\text {th }}$ line and $j^{\text {th }}$ column of the 
matrix $Q_{t}$. For the constant conditional correlation (CCC) case, $R_{t}=$ Rand $R_{i j}=\rho_{i j}$.

The MGARCH models are estimated by Quasi-Maximum Likelihood estimation (QMLE) using a joint normal density. T statistics are calculated using a robust estimate of the covariance matrix.

\section{Data}

The data for this study includes the daily closing prices of crude oil prices for Brent oil, considered a major world benchmark for oil prices, natural gas and seven clean energy stock price indices: Three global indices and four sectoral indices. The global indices were

a. The Wilder Hill Clean Energy Index (ECO), computed by the American stock Exchange, an equal-dollar-weighted index engaged in activities related with the use of cleaner energies and conservation.

b. The S \& P Global Clean Energy Index (S \& PGCE), computed as the weighted index composed of 30 companies and manufactures of clean energy and clean energy technologies around the world. And

c. The European Renewable Energy index (ERIX) which includes Europe's largest renewable energy companies generation involved in the production of wind power, solar energy, biomass and water.

The renewable energy sectoral indices were

a. The NYSE Bloomberg Global Wind Energy Index (WIND), an investable market index for only companies active across the wind energy sector, including equipment manufacture and the financing, development and operation of wind projects.

b. The NYSE Bloomberg Global Solar Energy Index (SOLAR), an investable market index for only companies active across the solar energy sector, including equipment manufacture and the financing, development and operation for solar projects.

c. The NYSE Bloomberg Global energy Smart Technologies Index (TECH), is comprised companies operating in the advanced transportation, digital energy, energy efficiency and energy storage sectors.

d. We use also the WilderHill New Energy Global Innovation Index (NEX) which is a modified dollar-weighted index of publicly traded companies active in renewable and low-carbon energy and whose technologies help reduce emissions relative to traditional fossil fuel use. Most of the index members quoted are from outside the US.

It is created by WilderHill New Energy Finance, LLC: DJI, with a benchmark value of 100 as on 30th December, 2002. In this paper, we use a daily data in our analysis which lets give clearer observations than weekly, monthly, yearly or quarterly data. Juan C Reboredo [6] found that daily data better examine the comovement and systemic risk between oil prices and stock prices of clean energy. The data for this study cover the period from $16 / 12 / 2005$ to $11 / 04 / 2016$ (with a total of 2698 observations) includes the daily closing prices of the ECO, the S \& PGCE, the ERIX, the WIND, the SOLAR, the TECH, the NEX, Brent crude oil and natural gas. Brent crude oil pricing data were obtained from the US Energy Information Agency, data on the ERIX were obtained from the Société Générale and data for other renewable energy indices were sourced from Data stream. Missing data arising from holidays and special events are supposed to be the average of the recorded previous price and the next price. Daily price returns for Brent and each price index were computed as the first difference of the natural logarithm between actual and previous price index multiplied by 100 :

$$
r_{t}=\left[\ln \left(P_{t}\right)-\ln \left(P_{t-1}\right)\right] \times 100
$$

Where $P_{t}$ : the closing of an index on day t and $P_{t-1}$ : the closing of an index on day $t-1$

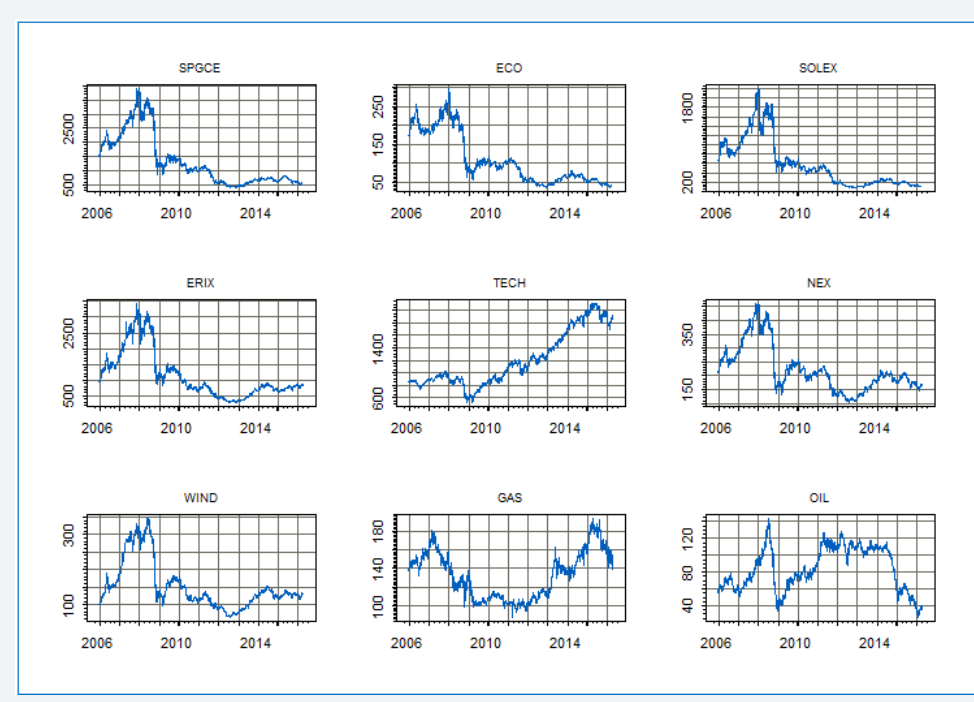

Figure 1 : Evolution of Brent, Gas and renewable energy index returns over time 

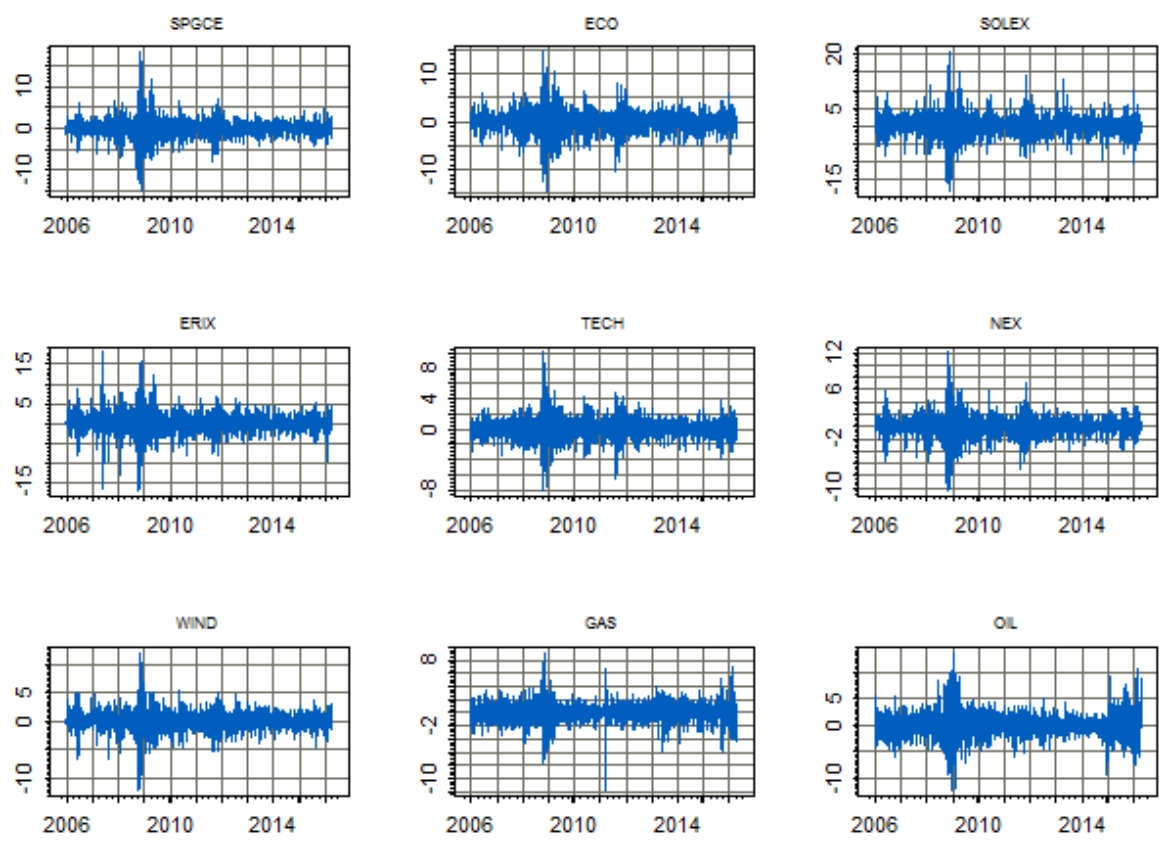

Figure 2: Price return dynamics of different indices over time

In order to illustrate the evolution of Brent, Gas and renewable energy indexes, we show their charts in Figure 1. We can clearly observe mean and variance of each stock index tend to move together. The recession of 2008-2009 had a big impact on the stock prices of clean energy companies as the ECO index suffered a huge drop of $-123 \%$ between September 1, 2008 and March 9, 2009. In addition, time series graphs show how volatility has changed across time. Figure 2 displays price return dynamics for Brent, Gas and renewable energy indices, showing differences in the size and timing of price movements around the onset of the recent global financial crises.

Table 1 reports descriptive statistics for price returns. For each series, average returns were close to zero or negative, suggesting lower performance, and the standard deviation is larger than the mean value. Skewness was positive for oil returns and negative for natural gas and renewable energy stocks, suggesting a greater probability of large decreases in gas and renewable energy returns than in oil returns. Each series displays a small amount of skewness and a larger amount of kurtosis, and the returns are not normally distributed, where by the Jarque-Bera [22] test strongly rejected the normality at the level of $5 \%$ of the unconditional distribution. The Ljung Box [23] statistics for serial correlation show that the null hypothesis of no autocorrelation is rejected, confirming serial autocorrelation in the energy price returns and squared returns. Also, the autoregressive conditional heteroskedasticity-Lagrange multiplier (ARCH-LM) statistic indicates that the series had ARCH effects. Finally, the results of the augmented Dickey \& Fuller [24] non-stationary test and the Kwiatkowski et al. [25] stationary test confirm that all return series were stationary. The Pearson correlation coefficient indicates that all renewable energy indices were positively correlated with oil price returns.

Table 1: Descriptive statistics for daily returns

\begin{tabular}{|c|c|c|c|c|c|c|c|c|c|}
\hline & OIL & SPGCE & ECO & SOLEX & ERIX & WIND & TECH & NEX & GAS \\
\hline Mean & -0.013 & -0.036 & -0.053 & -0.067 & -0.004 & 0.011 & 0.029 & -0.0095 & 0.00034 \\
\hline Std.dev & 2.081 & 2.06 & 2.19 & 2.85 & 2.41 & 1.59 & 1.27 & 1.58 & 1.35 \\
\hline Max & 13.687 & 18.092 & 14.519 & 20.619 & 18.038 & 12.048 & 10.098 & 12.07 & 9.21 \\
\hline Min & -12.307 & -14.972 & -14.467 & -18.326 & -17.249 & -12.229 & -8.12 & -10.485 & -11.92 \\
\hline Skewness & 0.133 & -0.479 & -0.337 & -0.256 & -0.324 & -0.598 & -0.183 & -0.447 & -0.229 \\
\hline Kurtosis & 4.031 & 11.299 & 4.614 & 6.037 & 8.47 & 8.085 & 5.683 & 6.784 & 6.083 \\
\hline
\end{tabular}




\section{Biostatistics and Biometrics Open Access Journal}

\begin{tabular}{|c|c|c|c|c|c|c|c|c|c|}
\hline JB & $1824.97^{*}$ & $14386.01^{*}$ & $2431.87^{*}$ & $4105.82^{*}$ & $8072.8^{*}$ & $7473.29^{*}$ & $3627.87^{*}$ & $5238.67^{*}$ & $4163.25^{*}$ \\
\hline $\mathbf{Q ( 1 2 )}$ & 11.754 & $75.27^{*}$ & 17.99 & $60.91^{*}$ & 21.08 & $81.25^{*}$ & 18.28 & $115.998^{*}$ & 20.642 \\
\hline $\mathbf{Q}^{\mathbf{2}} \mathbf{( 1 2 )}$ & $1043.48^{*}$ & $3506.51^{*}$ & $3059.70^{*}$ & $2275.25^{*}$ & $1793.14^{*}$ & $3298.07^{*}$ & $2464.23^{*}$ & $3029.407^{*}$ & $1084.99^{*}$ \\
\hline ARCH-LM & $586.118^{*}$ & $1111.801^{*}$ & $856.857^{*}$ & $766.11^{*}$ & $663.59^{*}$ & $1118.11^{*}$ & $782.85^{*}$ & $981.62^{*}$ & $429.28^{*}$ \\
\hline ADF & $-14.99^{*}$ & -44.53 & $-35.28^{*}$ & -44.97 & $-15.09^{*}$ & $-14.51^{*}$ & $-14.83^{*}$ & $-14.61^{*}$ & -16.41 \\
\hline KPSS & $0.29^{*}$ & $0.13^{*}$ & $0.06^{*}$ & $0.14^{*}$ & $0.23^{*}$ & $0.24^{*}$ & $0.13^{*}$ & $0.1^{*}$ & $0.1^{*}$ \\
\hline Corr.Brent & 1 & 0.117 & 0.17 & 0.115 & 0.35 & 0.39 & 0.2 & 0.38 & 0.046 \\
\hline
\end{tabular}

Notes: JB is the Jarque-Berax2 statistic for the test of normality. $Q(12)$ and $Q(12)^{2}$ are the Ljung-Box statistic checks for the serial correlation of squared standardized residuals. ARCH-LM is Engle's LM test for heteroskedasticity, computed using 20 lags. ADF and KPSS are the empirical statistics for the Augmented Dickey and Fuller and the Kwiatkowski stationarity test, respectively. Corr. Brent is the Pearson correlation for each series with Brent. An asterisk $\left({ }^{*}\right)$ indicates rejection of the null hypothesis at the $5 \%$ level.

\section{Empirical results and discussion}

This section reports on the empirical results obtained from estimating multivariate GARCH models.

Parameters roles: As the initial aim of this study is to measure the links existing between oil market and renewable energy market in terms of volatility, we will use a multivariate GARCH model. Especially, we estimate results of time-varying variance-covariance by the BEKK $(1,1)$ model. The system is given by:

$$
\begin{aligned}
& r_{t}=K+L r_{t-1}+\varepsilon_{t} \\
& H_{t}=C_{0}^{\prime} C_{0}+A^{\prime} \varepsilon_{t-1} \varepsilon_{t-1}^{\prime} A+B^{\prime} H_{t-1} B
\end{aligned}
$$

Where:

$$
\begin{aligned}
& r_{t}=\left(\begin{array}{l}
r_{t, p} \\
r_{t, i}
\end{array}\right), K=\left(\begin{array}{l}
k_{1} \\
k_{2}
\end{array}\right), L=\left(\begin{array}{ll}
l_{11} & 0 \\
l_{21} & l_{22}
\end{array}\right), \varepsilon_{t}=\left(\begin{array}{l}
\varepsilon_{t, 1} \\
\varepsilon_{t, 2}
\end{array}\right) \\
& C_{0}=\left(\begin{array}{cc}
C_{11} & 0 \\
C_{12} & C_{22}
\end{array}\right), A=\left(\begin{array}{ll}
a_{11} & a_{12} \\
a_{21} & a_{22}
\end{array}\right), B=\left(\begin{array}{ll}
b_{11} & b_{12} \\
b_{21} & b_{22}
\end{array}\right), H_{t}=\left(\begin{array}{ll}
h_{11, t} & h_{12, t} \\
h_{21, t} & h_{22, t}
\end{array}\right)
\end{aligned}
$$

To know more for the role of each parameter in each parameter in the system, we develop the mean and variance equations of model:

\section{Mean equation}

$$
\begin{aligned}
& \mathrm{r}_{1, \mathrm{t}}=\mathrm{k}_{1}+\mathrm{l}_{11} \mathrm{r}_{1 \mathrm{t}-1}+\varepsilon_{1 \mathrm{t}} \\
& \mathrm{r}_{2, \mathrm{t}}=\mathrm{k}_{2}+\mathrm{l}_{21} \mathrm{r}_{1 \mathrm{t}-1}+\mathrm{l}_{22} \mathrm{r}_{2 \mathrm{t}-1}+\varepsilon_{2 \mathrm{t}}
\end{aligned}
$$

\section{Variance equation}

$$
\begin{aligned}
\mathrm{h}_{11, \mathrm{t}}= & \mathrm{c}_{11}^{2}+\mathrm{c}_{21}^{2}+\mathrm{a}_{11}^{2} \varepsilon_{1 \mathrm{t}-1}^{2}+2 \mathrm{a}_{11} \mathrm{a}_{21} \varepsilon_{1 \mathrm{t}-1} \varepsilon_{2 \mathrm{t}-1}+\mathrm{a}_{21}^{2} \varepsilon_{2 \mathrm{t}-1}^{2}(12) \\
& +\mathrm{b}_{11}^{2} \mathrm{~h}_{1 \mathrm{t}-1}+2 \mathrm{~b}_{21} \mathrm{~b}_{11} \mathrm{~h}_{12, \mathrm{t}-1}+\mathrm{b}_{21}^{2} \mathrm{~h}_{2, \mathrm{t}-1} \\
\mathrm{~h}_{12, \mathrm{t}}= & \mathrm{c}_{11} \mathrm{c}_{12}+\mathrm{a}_{11} \mathrm{a}_{22} \varepsilon_{1 \mathrm{t}-1}^{2}+\left(\mathrm{a}_{12} \mathrm{a}_{21}+\mathrm{a}_{11} \mathrm{a}_{22}\right) \varepsilon_{1 \mathrm{t}-1} \varepsilon_{2 \mathrm{t}-1}+\mathrm{b}_{11} \mathrm{~b}_{12} \mathrm{~h}_{1, \mathrm{t}-1} \\
& +\left(\mathrm{b}_{12} \mathrm{~b}_{21}+\mathrm{b}_{11} \mathrm{~b}_{22}\right) \mathrm{h}_{12, \mathrm{t}-1}+\mathrm{b}_{21} \mathrm{~b}_{22} \mathrm{~h}_{2, \mathrm{t}-1} \\
\mathrm{~h}_{22, \mathrm{t}}= & \mathrm{c}_{12}^{2}+\mathrm{c}_{22}^{2}+\mathrm{a}_{12}^{2} \varepsilon_{1 \mathrm{t}-1}^{2}+2 \mathrm{a}_{12} \mathrm{a}_{22} \varepsilon_{1 \mathrm{t}-1} \varepsilon_{2 \mathrm{t}-1}+\mathrm{a}_{22}^{2} \varepsilon_{2 \mathrm{t}-1}^{2} \\
& +\mathrm{b}_{12}^{2} \mathrm{~h}_{1, \mathrm{t}-1}+2 \mathrm{~b}_{12} \mathrm{~b}_{22} \mathrm{~h}_{12, \mathrm{t}-1}+\mathrm{b}_{22}^{2} \mathrm{~h}_{2, \mathrm{t}-1}
\end{aligned}
$$

Where $h_{11, t}$ represent the conditional variance for crude oil market return at time $t, h_{12, t}$ indicate the conditional covariance between oil market return and those of renewable energy markets, and $h_{22, t}$ describes the conditional variance of renewable energy index returns. In addition, the parameters $a_{12}$, $a_{21}, b_{12}$ and $b_{21}$ show the transmission of volatility and shocks overtime between markets. Besides, the shock spillovers ( $\mathrm{a}_{12}$, and $a_{21}$, ) and volatility spillovers $\left(b_{12}\right.$ and $\left.b_{21}\right)$ off-diagonal elements of matrices $\mathrm{A}$ and $\mathrm{B}$, catch cross-market effects. Additionally, we can estimate the parameters of the bivariate GARCH model by the maximum likelihood estimation method optimized with the Berndt, Hall, Hall and Hausman (BHHH) algorithm.

\section{Parameters estimation of the bivariate VAR(1)- GARCH-BEKK(1,1) model}

As in the univariate case, it is assumed that the residuals are conditionally distributed according to a multivariate normal distribution with mean 0 and variance-covariance matrix $H_{t}$. In fact, results estimates are given in Table 2. This table shows the Ljung-Box Q statistics for the standardized residuals and squared standardized residuals of each index and for each system in order to check the existence of any linear or non-linear dependence. The $Q$ values show that the bivariate GARCH model generally provides a reasonable representation of the return process.

As mentioned below, Table 2 show the estimation results of our bivariate VAR(1)-GARCH-BEKK $(1,1)$ model for the eight pairs of oil-renewable energy returns. Regarding the extent of volatility transmission between Brent index and SPGCE, the coefficients $a_{12}$ and $\mathrm{a}_{21}$, are statistically significant. This result is interpreted as the conditional volatility of oil market is significantly influenced by unexpected changes coming from the SPGCE market. While, an oil shock can influence the volatility of SPGCE market. Then, we can say that the relationship is bidirectional. Among all indices, results estimations indicate that the volatility of oil price returns is significantly affected by its own news and its past volatility, due to the significance of coefficients $a_{11}$ and $b_{11}$. 


\section{Biostatistics and Biometrics Open Access Journal}

Table 2: Estimates of bivariate VAR (1)-GARCH-BEKK $(1,1)$ model for oil and renewable energy indices.

\begin{tabular}{|c|c|c|c|c|c|c|c|c|}
\hline \multicolumn{9}{|c|}{ OIL } \\
\hline Variables & SPGCE & ECO & SOLEX & ERIX & TECH & NEX & WIND & GAS \\
\hline$K_{1}$ & 0.0028 & -0.0027 & 0.0002 & 0.0179 & 0.0134 & 0.031 & 0.0252 & 0.018396 \\
\hline$K_{2}$ & 0.1533* & $0.0709 *$ & $0.1370^{*}$ & 0.0243 & $-0.0551^{*}$ & $0.1709^{*}$ & $0.111716^{*}$ & $-0.0737 *$ \\
\hline$l_{11}$ & $0.0957^{*}$ & $0.0926^{*}$ & $0.0886^{*}$ & $0.1094^{*}$ & 0.0941* & $0.0946^{*}$ & $0.092664^{*}$ & $0.08251 *$ \\
\hline$l_{21}$ & -0.0697 & -0.0819 & $-0.5438 *$ & $0.1786^{*}$ & 0.0659 & 0.0751 & 0.0712 & 0.0068 \\
\hline$l_{22}$ & $0.2508^{*}$ & $0.3605^{*}$ & 0.2424 & $0.4341^{*}$ & $0.1541^{*}$ & $0.1749 *$ & $0.2038^{*}$ & $0.2862^{*}$ \\
\hline$C_{11}$ & 0.022 & 0.0243 & 0.0313 & 0.0536 & 0.0187 & 0.0368 & 0.0515 & 0.0212 \\
\hline$C_{22}$ & 0.0395 & 0.0118 & 0.0555 & $0.0984^{*}$ & $0.0722^{*}$ & $0.0513^{*}$ & $0.0582 *$ & 0.0381 \\
\hline$a_{11}$ & $0.1770^{*}$ & $0.1792 *$ & $0.1326^{*}$ & $0.2081 *$ & $0.1975^{*}$ & $0.1980 *$ & $0.2043^{*}$ & 0.1904* \\
\hline$a_{21}$ & $0.0544^{*}$ & $0.0663^{*}$ & $0.2325^{*}$ & $0.0505^{*}$ & $0.0182 *$ & 0.009 & $0.0263^{*}$ & $0.0425^{*}$ \\
\hline$a_{12}$ & $-0.0324^{*}$ & -0.0167 & $-0.0380^{*}$ & 0.0198* & 0.038 & $0.0445^{*}$ & 0.0292 & -0.0165 \\
\hline$a_{22}$ & $0.3086^{*}$ & $0.3143^{*}$ & $0.3338^{*}$ & 0.2981* & $0.2752^{*}$ & $0.2894 *$ & $0.2600^{*}$ & $0.3524^{*}$ \\
\hline$b_{11}$ & 0.9821* & 0.9819* & $0.9857^{*}$ & $0.9780 *$ & $0.9806^{*}$ & $0.9812^{*}$ & 0.9799* & 0.9814* \\
\hline$b_{21}$ & $-0.0113^{*}$ & $-0.0116^{*}$ & $-0.0253^{*}$ & -0.0032 & -0.0018 & 0.0016 & -0.0005 & $-0.0082^{*}$ \\
\hline$b_{12}$ & $0.0183^{*}$ & $0.0129 *$ & $0.0263^{*}$ & -0.0062 & $-0.0147^{*}$ & $-0.0162 *$ & $-0.0119^{*}$ & 0.0095 \\
\hline$b_{22}$ & $0.9372 *$ & $0.9283^{*}$ & $0.8967 *$ & 0.9278* & 0.9491* & 0.9459* & 0.9498* & 0.9118* \\
\hline$Q_{1}(12)$ & 13.516 & 14.66 & 13.964 & 10.035 & 10.509 & 8.258 & 8.906 & 10.02 \\
\hline$Q_{2}(12)$ & 5.359 & 12.1 & 5.175 & 9.453 & 7.805 & 3.477 & 12.705 & 16.44 \\
\hline$Q_{1}^{2}(12)$ & 5.154 & 5.228 & 9.387 & 4.702 & 4.887 & 4.507 & 4.576 & 4.686 \\
\hline$Q_{2}{ }^{2}(12)$ & 7.555 & 12.333 & 8.028 & 8.225 & 16.718 & 8.883 & 11.557 & 8.096 \\
\hline AIC & 20927.12 & 21834.23 & 23287.84 & 22101.96 & 18737.55 & 19399.36 & 19650.53 & 19557.63 \\
\hline
\end{tabular}

Note: $Q(12)$ and $Q^{2}(12)$ are the Ljung-Box test statistic checks for the serial correlation of squared standardized residuals. The AIC criterion measures the relative goodness of fit of the estimated model. $\left(^{*}\right)$ indicate the rejection of the null hypothesis of associated statistic tests at the $5 \%$ level.

Beginning with the oil-NEX pair, the estimation results indicate that the volatility of the NEX is affected by the unexpected oil market news and the past conditional variance of oil market, as indicated by significantly sensitive to crude oil price. Indeed, the rise in oil prices may intensify the indices return volatility through changes in the oil. In terms of the ECO, TECH, WIND and GAS, our findings suggest that these indices have significant effect on the volatility of oil market. So, these indices are not affected by volatility in oil market. In this point, the performance of these indices is independent on oil price changes. The OIL-SPGCE, OIL-SOLEX and OIL-ERIX models show a bidirectional shock spillover between SPGCE, SOLEX, ERIX and

oil market. Additionally, we find that the $a_{11}$ and $a_{22}$ coefficients are statistically significant, indicating that an impact on the local market affects its conditional variance.

According to the Table 2 , we note that $b_{12}$ and $b_{21}$ coefficients are significant for all cases indicating the presence of volatility clustering phenomenon. Namely, periods of high (low) price changes are followed by periods of high (low) price fluctuations.

\section{Optimal portfolio weights and hedge ratios}

In order to hedge oil price change risk, portfolio managers are required to quantify the optimal weights and hedge ratio. Alternatively, an optimal portfolio weight of crude oil and 
renewable energy indices that minimizes risk without lowering expected returns can be calculated out using the following equation, Kroner \& Ng [26].

$$
w_{12, t}=\frac{\mathrm{h}_{22, \mathrm{t}}-\mathrm{h}_{12, \mathrm{t}}}{\mathrm{h}_{11, \mathrm{t}}-2 \mathrm{~h}_{12, \mathrm{t}}+\mathrm{h}_{22, \mathrm{t}}}
$$

Provided that,

$$
w_{12, t}=\left\{\begin{array}{c}
0, \operatorname{siw}_{12, t}<0 \\
w_{12, t}{\text { si } 0 \leq w_{12, t} \leq 1}_{1} \operatorname{siw}_{12, t}>1
\end{array}\right.
$$

Where, $w_{12, t}$ is the portfolio weight for the first index relative to the second index at time $t, h_{11, t}$ denotes the conditional variance of the first index, $h_{22, t}$ denotes the conditional variance of the second index and $h_{12, t}$ denotes the conditional covariance between the first and the second index. The optimal portfolio holdings for the medium-firm index would therefore be $\left(1-w_{12, t}\right)$.

We also estimate the risk minimizing hedge ratios for these indexes by using the ratio proposed by Kroner \& Sultan [27] who shows that to minimize the risk of a portfolio a long position in Table 3: Optimal portfolio weights, hedge ratio and conditional correlation for pairs of oil and renewable energy indices. one asset can be hedged with a short position in a second asset. This ratio is given by:

$$
\beta_{t}=\frac{h_{12, t}}{h_{22, t}}
$$

We present in Table 3 the average values of realized optimal weights $w_{12, t}$ and $\beta_{12, t}$. hedge ratios As shown in Table 3, the coefficients of optimal weights vary from one index to another and from MGARCH version to another. For example, the optimal weight for SPGCE-Oil portfolio is $43.63 \%, 43.58 \%, 43.79 \%$, $43.68 \%$ and $43.99 \%$ when using BEKK, CCC, DVEC, DCC-N and DCC-T versions of multivariate GARCH model respectively. The optimal weight for SOLEX-Oil portfolio is $64.64 \%$ for the BEKK version which indicate that the proportion of this portfolio in our optimal portfolio is $64.64 \%$ on average. The coefficients of average ratio are generally low, which suggest a very efficient hedge in equity indexes considered. If we consider for example, the effectiveness of the ECO-Oil hedge portfolio, which has a hedge ratio of 0.12820 across the DCC-GARCH model, which means that the hedging strategy of a long position on the oil

\begin{tabular}{|c|c|c|c|c|c|}
\hline Portfolio & $\begin{array}{l}\text { BEKK } \\
\text { GARCH }\end{array}$ & $\begin{array}{c}\text { CCC } \\
\text { GARCH }\end{array}$ & $\begin{array}{c}\text { DVEC } \\
\text { GARCH }\end{array}$ & DCC-N & $\begin{array}{l}\text { DCC-T } \\
\text { GARCH }\end{array}$ \\
\hline \multicolumn{6}{|c|}{ SPGCE/OIL } \\
\hline$w_{12, t}$ & 0.43636 & 0.43583 & 0.43798 & 0.4368 & 0.4399 \\
\hline$\beta_{12, t}$ & 0.06678 & 0.06595 & 0.04572 & 0.07896 & 0.07933 \\
\hline$\rho$ & 0.5322 & 0.53567 & 0.52411 & 0.06544 & 0.06596 \\
\hline \multicolumn{6}{|c|}{ ECO/OIL } \\
\hline$w_{12, t}$ & 0.51667 & 0.51761 & 0.5183 & 0.5184 & 0.521 \\
\hline$\beta_{12, t}$ & 0.136 & 0.14539 & 0.11537 & 0.1282 & 0.1281 \\
\hline$\rho$ & 0.56094 & 0.566 & 0.55245 & 0.1247 & 0.1247 \\
\hline \multicolumn{6}{|c|}{ SOLEX/OIL } \\
\hline$w_{12, t}$ & 0.64648 & 0.64373 & 0.640032 & 0.6422 & 0.6453 \\
\hline$\beta_{12, t}$ & 0.10877 & 0.10866 & 0.074069 & 0.05602 & 0.0559 \\
\hline$\rho$ & 0.53981 & 0.53776 & 0.525996 & 0.07089 & 0.0713 \\
\hline \multicolumn{6}{|c|}{ ERIX/OIL } \\
\hline$w_{12, t}$ & 0.5979 & 0.59535 & 0.597 & 0.59 & 0.5935 \\
\hline$\beta_{12, t}$ & 0.3766 & 0.38714 & 0.35716 & 0.2922 & 0.2894 \\
\hline$\rho$ & 0.654 & 0.65753 & 0.64613 & 0.3111 & 0.311 \\
\hline \multicolumn{6}{|c|}{ TECH/OIL } \\
\hline$w_{12, t}$ & 0.2395 & 0.24545 & 0.24357 & 0.2421 & 0.2481 \\
\hline
\end{tabular}
market should be covered by a short position of (12.82\%) in the ECO index. 
Biostatistics and Biometrics Open Access Journal

\begin{tabular}{|c|c|c|c|c|c|}
\hline$\beta_{12, t}$ & 0.1233 & 0.11644 & 0.11325 & 0.2993 & 0.2962 \\
\hline$\rho$ & 0.5908 & 0.59179 & 0.58514 & 0.1774 & 0.177 \\
\hline \multicolumn{6}{|c|}{ NEX/OIL } \\
\hline$w_{12, t}$ & 0.2942 & 0.29481 & 0.29514 & 0.2917 & 0.2975 \\
\hline$\beta_{12, t}$ & 0.2452 & 0.25147 & 0.23927 & 0.4792 & 0.4758 \\
\hline$\rho$ & 0.6598 & 0.66682 & 0.65608 & 0.3225 & 0.3228 \\
\hline \multicolumn{6}{|c|}{ WIND/OIL } \\
\hline$w_{12, t}$ & 0.3136 & 0.31968 & 0.32237 & 0.316 & 0.3249 \\
\hline$\beta_{12, t}$ & 0.253 & 0.2702 & 0.24731 & 0.316 & 0.47 \\
\hline$\rho$ & 0.6628 & 0.67164 & 0.65603 & 0.3306 & 0.3309 \\
\hline \multicolumn{6}{|c|}{ GAS/OIL } \\
\hline$w_{12, t}$ & 0.32652 & 0.32746 & 0.32934 & 0.3273 & 0.3275 \\
\hline$\beta_{12, t}$ & 0.02508 & 0.01995 & 0.01437 & 0.03589 & 0.0385 \\
\hline$\rho$ & 0.51261 & 0.51367 & 0.50849 & 0.02522 & 0.02667 \\
\hline
\end{tabular}
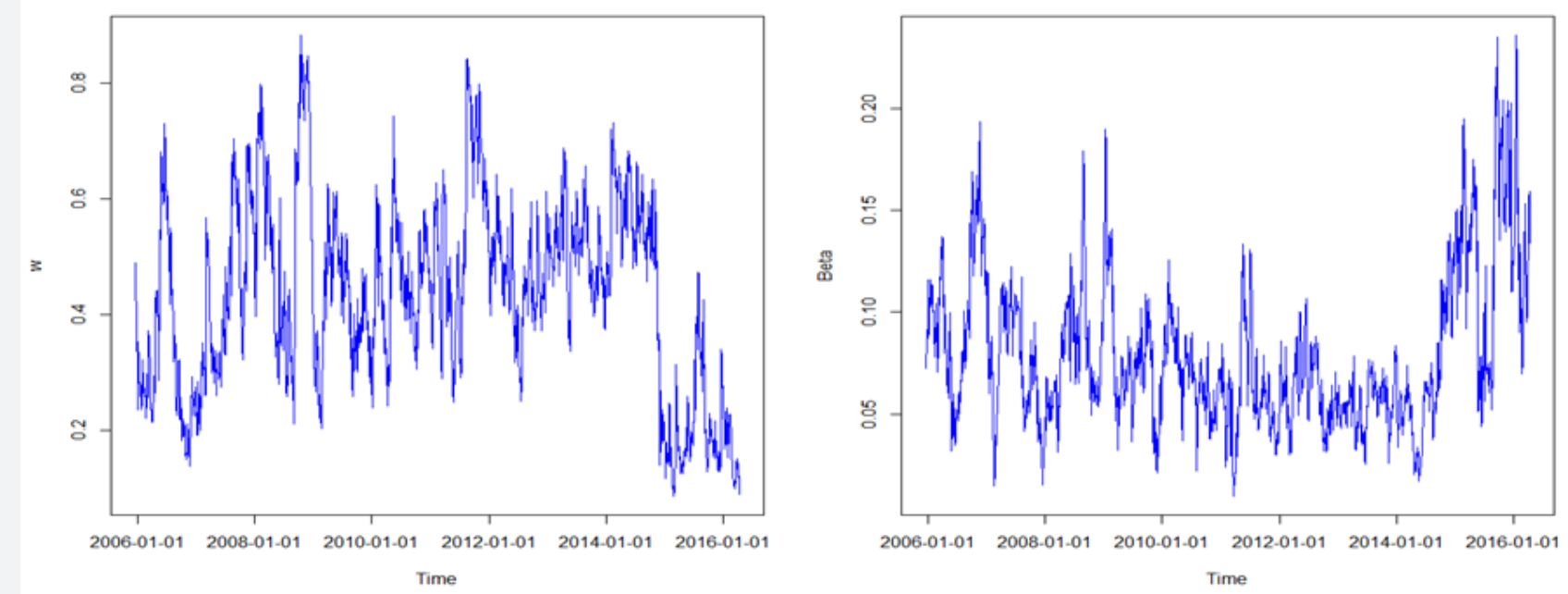

Figure 3 : Evolution of the optimal weights and hedge ratios of the optimal portfolio for the SPGCE-Oil portfolio from the DCC-N-GARCH model.

Concerning the conditional correlation coefficients $\rho$, we note that for the different indices, these coefficients are positive and over $50 \%$ for the versions: BEKK-CCC-DVEC, MGARCH model. This indicates that there is a little flexibility for portfolio diversification between different series. On the other hand, for the DCC-T versions, the averages of $\rho$, are less than $50 \%$. In summary, our findings provide an important guideline on building optimal risk portfolios between oil and renewable energy market, and some benefits from the optimal diversifiable portfolio to minimize the oil price risk without any impairment of expected returns. Figure 3 shows the evolution of the optimal weights and hedge ratios of the optimal portfolio for the SPGCE Oil portfolio from the DCC-N-GARCH model.

\section{Performance of different versions and hedging effectiveness}

Our goal in this section is to study the performance of each version of MGARCH model to give a better hedging strategy against risks. We try to compare these different versions to show in a first step the benefits of using the MGARCH model in 


\section{Biostatistics and Biometrics Open Access Journal}

reducing risks and in a second step to choose the best version of MGARCH model. The effectiveness of hedging across constructed portfolios can be evaluated by examining the realized hedging errors, which determined by Ku et al. [28] and Chang et al. [29] as follows:

$$
H E=\left(\frac{V a r_{\text {unhedged }}-V a r_{\text {hedged }}}{V a r_{\text {unhedhed }}}\right)
$$

Where, the variances of the unhedged portfolio $\left(\right.$ Var $\left._{\text {unhedged }}\right)$ are the variances of the return on the portfolio of stocks with $100 \%$ oil and $0 \%$ renewable energy, whereas the variances of the hedge portfolio ( $\left.V a r_{\text {unhedged }}\right)$ are obtained from the optimal portfolio. A higher HE index indicates a higher hedging effectiveness, which indicates that the associated investment method can be deemed a better hedging strategy. Table 4 shows the average values of mean return, average standard deviation, risk adjusted return, and hedging effectiveness (HE) ratios of each portfolio using four different versions of MGARCH model: BEKK, CCC, DVEC and DCC (Normal and student).

A risk adjusted return of each portfolio is determined as follow:

$$
R-R A=\frac{\text { Meanreturn }}{\text { Standarddeviation }} \times 100
$$

A first selection criterion is to choose the method that has the standard deviation at minimum risk. From Table 4, we can see that the four versions of MGARCH model record a standard deviation average which are very close to each other. This shows the effectiveness of the portfolio diversification by introducing the Brent index in the risk minimization.

\begin{tabular}{|c|c|c|c|c|c|}
\hline Portfolio & Mean & Variances & Standard deviation & $\begin{array}{c}\text { Realized risk } \\
\text { adjusted returns } \\
(* 100)\end{array}$ & HE \\
\hline \multicolumn{6}{|c|}{ OIL-SPGCE } \\
\hline BEKK-GARCH & -0.00053 & 4.347073 & 1.922993 & -0.027655 & 0.040163 \\
\hline CCC-GARCH & -0.01236 & 4.344625 & 1.922588 & -0.6427649 & 0.00509 \\
\hline DVEC-GARCH & -0.01019 & 4.369966 & 1.926516 & -0.528964 & 0.003486 \\
\hline DCC-N & -0.00962 & 4.350531 & 1.582161 & -1.999657 & 0.005633 \\
\hline DCC-t & -0.00935 & 4.322048 & 1.919433 & -0.4872855 & 0.006452 \\
\hline \multicolumn{6}{|c|}{ OIL-ECO } \\
\hline BEKK-GARCH & -0.00059 & 4.257338 & 1.914752 & -0.03058773 & 0.058995 \\
\hline CCC-GARCH & -0.00631 & 4.319251 & 1.917657 & -0.3292292 & 0.017427 \\
\hline DVEC-GARCH & -0.00689 & 4.277092 & 1.911514 & -0.3602743 & 0.014874 \\
\hline DCC-N & -0.00532 & 4.293226 & 1.913406 & -0.2781735 & 0.018731 \\
\hline DCC-t & -0.00561 & 4.26369 & 1.907748 & -0.2940825 & 0.019868 \\
\hline \multicolumn{6}{|c|}{ OIL-SOLEX } \\
\hline BEKK-GARCH & -0.00784 & 4.370358 & 1.926498 & -0.4068353 & 0.037089 \\
\hline CCC-GARCH & -0.01044 & 4.34708 & 1.923189 & -0.5427629 & 0.005705 \\
\hline DVEC-GARCH & -0.01151 & 4.349734 & 1.925024 & -0.5979855 & 0.003406 \\
\hline DCC-N & -0.00926 & 4.345883 & 1.924433 & -0.4809391 & 0.006696 \\
\hline DCC-t & -0.00896 & 4.319615 & 1.918973 & -0.467017 & 0.007012 \\
\hline \multicolumn{6}{|c|}{ OIL-ERIX } \\
\hline BEKK-GARCH & -0.007 & 3.703282 & 1.794676 & -0.3901623 & 0.162032 \\
\hline CCC-GARCH & -0.01659 & 3.87343 & 1.823802 & -0.9097361 & 0.099263 \\
\hline DVEC-GARCH & -0.01267 & 3.773431 & 1.805197 & -0.7018249 & 0.125023 \\
\hline DCC-N & -0.0101 & 3.790041 & 1.803906 & -0.5596676 & 0.13374 \\
\hline DCC-t & -0.01051 & 3.783711 & 1.801917 & -0.5831 & 0.130205 \\
\hline \multicolumn{6}{|c|}{ OIL-TECH } \\
\hline BEKK-GARCH & -0.02865 & 4.028609 & 1.856515 & -1.54302 & 0.087463 \\
\hline CCC-GARCH & -0.02174 & 4.239582 & 1.900447 & -1.143812 & 0.033702 \\
\hline DVEC-GARCH & -0.03166 & 4.067965 & 1.86033 & -1.70164 & 0.068829 \\
\hline DCC-N & -0.03217 & 4.087872 & 1.862971 & -1.726557 & 0.065667 \\
\hline
\end{tabular}

Table 4: Mean, variances, standard deviations and risk-adjusted returns of optimal portfolio obtained by different methods. 


\section{Biostatistics and Biometrics Open Access Journal}

\begin{tabular}{|c|c|c|c|c|c|}
\hline DCC-t & -0.03159 & 4.084555 & 1.862304 & -1.696478 & 0.061047 \\
\hline \multicolumn{6}{|c|}{ OIL-NEX } \\
\hline BEKK-GARCH & -0.01353 & 3.589034 & 1.76874 & -0.7649753 & 0.187552 \\
\hline CCC-GARCH & -0.01805 & 3.805081 & 1.808155 & -0.9981231 & 0.111318 \\
\hline DVEC-GARCH & -0.02124 & 3.615392 & 1.768131 & -1.20127 & 0.160614 \\
\hline DCC-N & -0.0223 & 3.687767 & 1.778488 & -1.253948 & 0.157116 \\
\hline DCC-t & -0.02214 & 3.668995 & 1.775098 & -1.247163 & 0.156576 \\
\hline \multicolumn{6}{|c|}{ OIL-WIND } \\
\hline BEKK-GARCH & -0.01219 & 3.514757 & 1.757109 & -0.6938088 & 0.200819 \\
\hline CCC-GARCH & -0.02391 & 3.747009 & 1.795037 & -1.331903 & 0.117847 \\
\hline DVEC-GARCH & -0.01748 & 3.627656 & 1.773237 & -0.9858667 & 0.155382 \\
\hline DCC-N & -0.02046 & 3.664096 & 1.77925 & -1.150144 & 0.162527 \\
\hline DCC-t & -0.02086 & 3.655093 & 1.777049 & -1.174046 & 0.159771 \\
\hline \multicolumn{6}{|c|}{ OIL-GAS } \\
\hline BEKK-GARCH & -0.02059 & 4.323386 & 1.921939 & -1.071501 & 0.028075 \\
\hline CCC-GARCH & -0.01233 & 4.383271 & 1.931313 & -0.6386031 & 0.000748 \\
\hline DVEC-GARCH & -0.01592 & 4.358291 & 1.924792 & -0.8272276 & 0.004234 \\
\hline DCC-N & -0.0153 & 4.357532 & 1.926291 & -0.7942082 & 0.004033 \\
\hline DCC-t & -0.01502 & 4.33563 & 1.921708 & -0.7815551 & 0.00333 \\
\hline
\end{tabular}

Results show that the portfolio OIL/WIND has the highest hedge effectiveness coefficient (HE) with $20 \%$. However, the lowest coefficient is recorded in the portfolio OIL/GAS for a value of $2.8 \%$. Moreover, the lowest and highest HE ratios are given by the BEKK-GARCH. So, we conclude that an investor who wants to invest in the renewable energy market, the best model that provide the best hedging effectiveness and minimizes greatly the risk of its portfolio during the whole period is the OIL/WIND. Therefore, our results prove that the BEKK-GARCH model is the best version adopted in all cases to minimize the risk of oil-stock portfolio (Table 5).

Table 5: Summary table.

\begin{tabular}{|c|c|c|c|c|c|}
\hline Objectify & ВEKK & CCC & DVEC & DCC-N & DCC-T \\
\hline $\begin{array}{l}\text { Max } \\
\text { return }\end{array}$ & $\begin{array}{c}\text { SPGCE } \\
\text { ECO } \\
\text { SOLEX } \\
\text { ERIX } \\
\text { NEX } \\
\text { WIND }\end{array}$ & $\begin{array}{c}\text { TECH } \\
\text { GAS }\end{array}$ & & & \\
\hline $\begin{array}{c}\text { Min } \\
\text { variance }\end{array}$ & $\begin{array}{c}\text { ECO } \\
\text { ERIX } \\
\text { TECH } \\
\text { NEX } \\
\text { WIND } \\
\text { GAS }\end{array}$ & & & & $\begin{array}{c}\text { SPGCE } \\
\text { SOEX }\end{array}$ \\
\hline Min risk & $\begin{array}{c}\text { ERIX } \\
\text { TECH } \\
\text { WIND }\end{array}$ & & NEX & SPGCE & $\begin{array}{c}\text { ECO } \\
\text { SOLEX } \\
\text { GAS }\end{array}$ \\
\hline
\end{tabular}

\begin{tabular}{|c|c|c|l|l|l|}
\hline & SPGCE & & & & \\
Max & ECO & & & \\
return/ & SOLEX & TECH & & & \\
Min risk & ERIX & GAS & & & \\
& NEX & & & \\
& WIND & & & \\
& SPGCE & & & \\
& ECO & & & \\
& SOLEX & & & \\
Max HE & ERIX & & & \\
& TECH & & & \\
& NEX & & & \\
& WIND & & & \\
& GAS & & & \\
\hline
\end{tabular}

\section{Conclusion}

This paper investigated correlations and the volatility spillovers between Brent oil and stock prices of clean energy companies and analyzed the optimal weights and hedge ratio for building optimal portfolio to minimize the risk. Empirical results show that the volatility of the alternative energy market can be influenced by the unexpected changes in oil market and vice versa. In addition, the optimal weights and hedge ratio in the hedged portfolios varies from pair Oil/Renewable Energy to another, from period to another and from version MGARCH to another.

Although, the DCC model is more advantageous than other MGARCH versions, the results of our study show that the BEKK 
model is more effective than the others models to minimize the risk of Oil-Renewable Energy portfolio. The most important result found is that hedge against the risk of oil price fluctuations is effective with the use of renewable energy markets (as $\mathrm{W} \neq 0$ ) but the optimal weight $\mathrm{W}$ report values which vary between $10 \%$ and $80 \%$ depending on conditions. Future researches can extend this methodology to multivariate contexts to use more advanced versions of MGARCH model, such as ADCC (Asymmetric DCC), taking account the asymmetry information. Moreover, future studies may be interested in using copula theory to improve the quality of dependency modeling.

\section{References}

1. Ripsy B, Sajal G, Kakali K (2016) International crude oil prices and the stock prices of clean energy and technology companies: Evidence from non-linear cointegration tests with unknown structural breaks. Energy 101: 558-565.

2. Shunsuke M, Shunsuke M, Tatsuyoshi O (2013) Does the price of oil interact with clean energy prices in the stock market? Japan and the World Economy 27: 1-9.

3. Beenstock M (1977) The depletion of UK oil resources. Energy 2(3): 56-249.

4. International Energy Agency (2009) World Energy Outlook. IEA, Paris.

5. Perry S (2012) Correlations and volatility spillovers between oil prices and the stock prices of clean energy and technology companies. Energy Economics 34(1): 248-255.

6. Juan CR (2015) Is there dependence and systemic risk between oil and renewable energy stock prices?. Energy Economics 48: 32-45.

7. Martin TB, Philipp K, Patrick MS (2013) From Hero to Zero: Evidence of Performance Reversal and Speculative Bubbles in German Renewable Energy Stocks. Energy Economics 37: 40-51.

8. Henriques I, Sadorsky P (2008) Oil prices and the stock prices of alternative energy companies. Energy Economics 30: 998-1010.

9. Kumar S, Managi S, Matsuda A (2012) Stock prices of clean energy firms, oil and carbon markets: a vector autoregressive analysis. Energy Economics 34(1): 215-26.

10. Toda HY, Yamamoto $T$ (1995) Statistical inference in vector autoregressions with possibly integrated processes. Journal of Econometrics 66(1-2): 225-250.

11. Broadstock DC, Cao H, Zhang D (2012) Oil shocks and their impact on energy related stocks in china. Energy Economics 34: 1888-1895.

12. Sadorsky P (2012) Modeling renewable energy company risk. Energy Policy 40: 39-48.

13. Betzer A, Doumet M, Rinne U (2011) How Policy Changes Affect Shareholder Wealth: The Case of the Fukushima Daiichi Nuclear Disaster. Working Paper, Institute for the Study of Labor Bonn, Germany, UK.
14. Ferstl R, Utz S, Wimmer M (2012) The Effect of the Japan 2011 Disaster on Nuclear and Alternative Energy Stocks Worldwide: An Event Study. BuR -Business Research 5(1): 25-41.

15. Ortas E, Moneva JM (2013) The Clean Techs equity indexes at stake: risk and return dynamics analysis. Energy 57(1): 259-269.

16. Wen X, Guo Y, Wei Y, Huang D (2014) How do the stock prices of new energy and fossil fuel companies correlate? Evidence from China. Energy Economics 41: 63-75.

17. Engle RF, Kroner KF (1995) Multivariate simultaneous generalized ARCH. Econometric Theory 11: 122-1250.

18. Bollerslev T (1990) Modeling the coherence in short-run nominal exchange rates: A multivariate generalized ARCH approach. Review of Economics and Statistics 72: 498-505.

19. Engle RF (2002) Dynamic conditional correlation: a simple class of multivariate generalized autoregressive conditional heteroskedasticity models. Journal of Business \& Economic Statistics 20: 339-350.

20. Bollerslev $\mathrm{T}$ (1986) Generalized autoregressive conditional heteroskedasticity. Journal of Econometrics 31(3): 307-327.

21. Ling S, McAleer M (2003) Asymptotic theory for a vector ARMA-GARCH model. Econometric Theory 19: 278-308.

22. Jarque C, Bera A (1980) Efficient tests for normality homoscedasticity and serial independence of regression residuals. Economics Letters 6(3): 255-259.

23. Ljung M, Box G (1978) On a measure of lack of fit in time series models. Biometrika 65: 297-303.

24. Dickey DA, Fuller WA (1979) Distribution of the estimators for autoregressive time series with a unit root. Journal of the American Statistical Association 75: 427-431.

25. Kwiatkowski D, Phillips PCB, Schmidt P, Shin Y (1992) Testing the null hypothesis of stationary against the alternative of a unit root. Journal of Economics 54(1-2): 159-178.

26. Kroner KF, Ng VK (1998) Modeling asymmetric movements of asset prices. Review of Financial Studies 11: 844-871.

27. Kroner KF, Sultan J (1993) Time-varying distributions and dynamic hedging with foreign currency futures. Journal of Financial and Quantitative Analysis 28: 535-551.

28. Ku YH, Chen H, Chen K (2007) On the application of the dynamic conditional correlation model in estimating optimal time varying hedge ratios. Applied Economics Letters 7: 503-509.

29. Chang CL, McAleer M, Tansuchat R (2011) Futures hedging effectiveness under the segmentation of bull/bull energy markets. Energy Economics 32: 442-449. 

(C) C) This work is licensed under Creative

DOI: 10.19080/BBOAJ.2018.06.555687

\section{Your next submission with Juniper Publishers} will reach you the below assets

- Quality Editorial service

- Swift Peer Review

- Reprints availability

- E-prints Service

- Manuscript Podcast for convenient understanding

- Global attainment for your research

- Manuscript accessibility in different formats

( Pdf, E-pub, Full Text, Audio)

- Unceasing customer service

Track the below URL for one-step submission https://juniperpublishers.com/online-submission.php 